Celal Bayar University Journal of Science

\title{
Optimal placement of multiple DGs in radial distribution systems to minimize power loss using BSA
}

\author{
Waleed Fadel ${ }^{1 *}$ (D), Ulaş Kılıç2 (iD), Sezai Taşkın³ (iD) \\ ${ }^{1}$ Department of Electrical\&Electronics, Faculty of Engineering, Girne American University, Mersin 10 - Turkey \\ ${ }^{2}$ Department of Electrical\&Electronics, Faculty of Engineering, Ege University, İzmir - Turkey \\ ${ }^{3}$ Department of Electrical\&Electronics, Faculty of Engineering, Manisa Celal Bayar University, Manisa -Turkey \\ *waleedfadel@gau.edu.tr \\ *Orcid: 0000-0002-5061-6474
}

Received: 18 September 2020

Accepted: 29 March 2021

DOI: $10.18466 /$ cbayarfbe. 796140

\begin{abstract}
Distributed generation (DG) sources are becoming more important in electrical networks due to the increase of electrical energy demands. However, DG sources can have a profound effect on network power loss. Hence, optimal placement and size of DGs are extremely important. This study presents an efficient heuristic algorithm based on optimal placement and size of multiple DGs within distribution systems in order to reduce power loss. This algorithm is backtracking search algorithm (BSA). Two main DGs, photovoltaic and synchronous compensator, are integrated in two different radial distribution systems (RDS), IEEE 33-bus system and IEEE 69-bus system. To demonstrate the effectiveness of the proposed method, the results obtained by BSA are compared with a genetic algorithm (GA) as well as other results in the literature.
\end{abstract}

Keywords: BSA, DG placement, DG size, power loss.

\section{Introduction}

The integration of a solar power plant in distribution network is an important challenge, and it is one of the ways to reduce the environmental pollution that is produced by fossil fuel-based energy generation. Thus, much research has been concentrated on the optimum integration of solar panels in distribution networks in recent years.

Optimal reactive power flow is necessary to maintain power system reliability. It is achieved by minimizing power losses in the transmission line under the constraints of the physical system, using power flow equations. Valuable articles have dealt with this subject for the purpose of reducing power losses. Kansal et al. [1] proposed particle swarm optimization (PSO) to solve for the placement and size of different types of DG's, taking the power loss as an objective function. Kayal et al. [2] presented different types of DG's with different modes, using PSO. Their objective was power loss minimization and voltage stability improvement. Kollu et al. [3] proposed a harmony search algorithm (HSA) for multi-DG placement to reduce power loss, and enhance the voltage profile. García et al. [4] employed modified teaching-learning based optimization (MTLBO) to solve the problem of placement and sizing of multiple DG's with the single objective of reducing power loss. Injeti et al. [5] used simulated annealing (SA) for a DG placement and size to reduce the power loss, and improve the voltage stability. Manafi et al. [6] presented dynamic PSO for optimal placement of a DG to minimize power loss. Moradi et al. [7] proposed PSO/GA hybrid algorithms as a solution for sizing and placement of a DG to improve voltage regulation, and minimize power loss. Aman et al. [8] employed a PSO algorithm to solve a function with the multiple objectives of maximizing voltage stability and minimizing power losses, and found the optimal DG allocation, weakest link in the network, and the most sensitive voltage bus. Ates et al. [9] examined the impact of hybrid DG on power losses, voltage improvement, and electricity bill in distribution network by using the ETAP. Turan et al. [10] proposed the integration of a solar plant to a PEV parking lot to reduce power consumption and losses considering various operating conditions. Hemeida et. al. [11] implemented a new optimization algorithm to the optimal integration of a DG for power loss minimization. Memarzadeh et al. [12] applied a new approach for DG placement in order to improve voltage stability index and 
the system reliability. This approach has been tested in various RDS. Kansal et al. [13] proposed a hybrid of heuristic and analytical methods of the PSO (H-PSO) algorithm to determine the optimum places and the best types of DGs.

In this work, we have considered 3 scenarios. In Scenario 1 , the tested systems are integrated by activepower DGs (photovoltaic) only, where only one activepower DG can be placed in a given bus. In Scenario 2, one active-power DG and one reactive-power DG (synchronous compensator) are paired and connected together in a bus, where only one pair can be placed in a given bus. In Scenario 3, while in some buses one activepower DG and one reactive-compensator DG are paired and connected as a single pair per bus, in other buses either one active-power DG or one reactive-power DG is placed singly -only one DG per bus. References [2, 5, 6, 7, 8 and 13] dealt only with scenario 1 . Ref. [1] dealt with scenarios 1 and 2, but not 3. None of the references used the BSA in their optimizations. In this paper, we applied the BSA on 33-bus as well as 69-bus systems in cases where multiple DGs (up to a total of 16 DGs and 13 buses) are used. As understood from the Ref. [1-8] mentioned above, heuristic algorithms are successfully applied to solve the optimization problem in RDS. In this study, we used the BSA to solve the optimization problem of DG placement and sizing, such as to minimize system power loss in RDS.

This paper is arranged as follows: problem formulation is in Section 2, the proposed algorithm in Section 3, simulation results and discussion in Section 4, and the conclusion in Section 5.

\section{Problem formulation}

In this paper, active power loss is selected as an objective function. To minimize the objective function, the proposed algorithm is applied in two RDSs under both equality as well as inequality constraints. Minimization of power loss is an optimization problem, mathematical equations of which is well known and is defined as follows,

$\begin{array}{ll}\text { Minimize } & f(x, u) \\ \text { Such that } & g(x, u)=0 \\ & h(x, u) \leq 0\end{array}$

where $f, g$, and $h$ are the fitness function, the equality constraint, and the inequality constraint, respectively. Here, $x$ is the vector of control variables, while $u$ is the vector of state variables. The control variables are the size and the place of DG active power, and of the reactive compensators. The state variables are active and reactive power of the feeder, load, bus voltage, and the line current.

\subsection{Objective Function}

In this work, power loss is selected as an objective function. The power loss can be demonstrated as equation (2) [14].

$$
P_{\text {loss }}=P_{\text {feeder }}+\sum_{i=1}^{N_{D G}} P_{D G, i}-\sum_{i=1}^{N} P_{\text {Load }, i} \quad i=1, \ldots, N
$$

\subsection{Equality constraints}

Load balancing constraint formulas as follows:

$$
\begin{gathered}
C D G_{i} \cdot P_{D G, i}+C F_{i} \cdot P_{\text {feeder }}=P_{\text {Load }, i}+V_{i} \sum_{j=1}^{N} V_{j}\left(G_{i j} \cos \delta_{i j}+B_{i j} \sin \delta_{i j}\right) \\
i=1, \ldots, N \\
C S C \cdot Q_{s c, i}+C F_{i} \cdot Q_{\text {feeder }}=Q_{\text {Load }, i}+V_{i} \sum_{j=1}^{N} V_{j}\left(G_{i j} \sin \delta_{i j}-B_{i j} \cos \delta_{i j}\right) \\
\quad i=1, \ldots, N
\end{gathered}
$$

\subsection{Inequality constraints}

\section{Voltage limits:}

The allowable range for all buses is given in equation (5),

$V_{i}^{\min } \leq V_{i} \leq V_{i}^{\max }$ $i=1, \ldots, N$

Unit constraints of DGs:

The following constraint is the allowable active power and reactive power sizes of DGs.
$P_{D G, i}^{\min } \leq P_{D G, i} \leq P_{D G, i}^{\max }$
$i=1, \ldots, N_{D G}$

(6)

$$
Q_{s c, i}^{\min } \leq Q_{s c, i} \leq Q_{s c, i}^{\max } \quad i=1, \ldots, N_{S C}
$$

\section{Line capacity constraints:}

The current limitation of the distribution lines of the system is given by [15].

$$
\left|I_{i j}\right| \leq\left|I_{i j}^{\max }\right| \quad i=1, \ldots, N, j=1, \ldots, N \text { and } i \neq j
$$

\section{Back-tracking Search Algorithm}

BSA is an evolutionary algorithm (EA) introduced by Civicioglu in 2012 [16]. BSA has been applied to solve different optimization problems in various fields such as energy, geophysics, and magnetism [17-19]. The most significant property of BSA that it is not sensitive to the initial values. Selection, mutation, and crossover 
operators are used in BSA. The MATLAB ${ }^{\circledR}$ code of BSA can be found in [16]. The basic steps of BSA are outlined as follows [17].

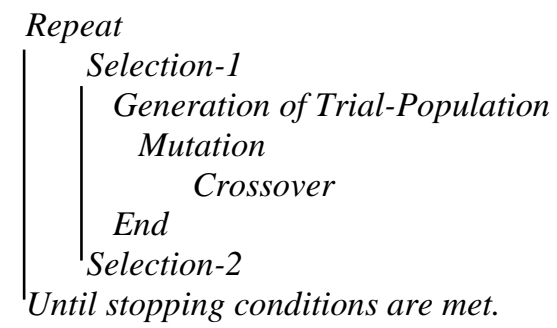

\subsection{Initialization}

In the beginning, two different populations ( Pop and oldPop ) are formed as follows:

$$
\begin{aligned}
& \operatorname{Pop}_{i, j} \sim \operatorname{Rand}\left(\operatorname{low}_{j}, \text { up }_{j}\right) i=1, \ldots, S \mathrm{~N}_{j}=1, \ldots ., D \\
& \operatorname{oldPop}_{i, j} \sim \operatorname{Rand}\left(\operatorname{low}_{j}, \text { up }_{j}\right) i=1, \ldots, S \mathrm{~N}_{j}=1, \ldots ., D
\end{aligned}
$$

\subsection{Selection-I}

In this section, the old population (oldPop) in the initiation stage is formed using,

if $a<b, \quad$ oldPop $:=$ Pop $\quad$ end $\mid a, b \sim \operatorname{Rand}(0,1)$

In equation $(11),:=$ is the update operator. This operator randomly transfers the Pop individuals' variables to oldPop individuals' variables. Then, equation (12) is used to randomly change individuals in the oldPop .

oldPop := Randshuff (oldPop)

where Randshuff is a random mixing function [15].

\subsection{Mutation}

The mutation process is formed as

$$
\text { mutantPop }=\text { Pop }+W(\text { oldPop }- \text { Pop })
$$

In equation (13), $W$ controls the amplitude of the search line matrix. $W=3$ randn is proposed in the Ref.[16]. However, we observed that the performance of 4 is better that of 3 . The function "randn" randomly generates numbers between 0 and 1 according to the standard normal distribution [17].

\subsection{Crossover}

\section{Initialization}

In this section, the trial population (Tpop) is formed using equation (14). The crossover process consists of two stages. In the first stage, the binary number system is fully valued, and produces $S N * D$ size of a matrix (map). This matrix is used to determine whether or not we have to modify Tpop, one row at a time ("individual by individual" in heuristic terms). The second stage, the following equation is obtained from the matrix after its formation.

if map $_{i, j}=1$ then Tpop $_{i, j}=$ Pop $_{i, j} \quad$ else Tpop Tp $_{i, j}=$ mutantPop $_{i, j}$ end

\subsection{Selection-II}

All the "individual" fitness values produced is calculated in this section. Individuals are sorted according to their fitness values, from best to worst. Then, the SN of them are carried to the next iteration Pop . The remaining ones are omitted. In this way, the best "individuals" among the whole population are transferred to the next generation.

\section{Simulation Results and discussion}

In this work, two types of DG are integrated in two different RDS. These systems are 33 and 69 bus systems. All nodes integrated of DGs are selected as PQ mode. The results are compared with GA and other recent works.

DG resources are divided into 4 types, determined by ability to deliver active and reactive power. The DG types are:

Type I: Generating active power (Photovoltaic system). Type II: Generating reactive power (Synchronous compensation).

Type III: Generating active and absorbing reactive power (Wind power)

Type IV: Generating active and reactive power (Synchronous generator).

Type I and Type II are performed in our work.

\section{Scenarios and cases}

In this study, 3 scenarios and 5 cases are examined. All scenarios are considered under the 5 cases, and the differences between cases, depend on the number of DGs. In the following tables Case1 is base case for IEEE 33- bus system and IEEE 69- bus system.

Scenario1: All DGs are type I, one per bus. 
Scenario2: Any pair of DGs (one of type I \& one of type II) is connected in the same bus, only one pair per bus.

Scenario3: Some DG pairs (one of type I \& one of type II) are connected in the same bus, one pair bus, while single DGs (type-I or type-II) are connected in different buses, one DG per bus.

\subsection{IEEE 33-bus system}

The IEEE 33-bus system is selected, with a system voltage base of $12.66 \mathrm{kV}$ for all cases, and base apparent power of $100 \mathrm{MVA}$ for all cases. The test system has total active and reactive loads of $3.715 \mathrm{MW}$ and 2.300 MVAr, respectively. The data for the line reactance and resistances, and for the loads connected to buses, are given in [20].

Scenario1: In scenario1, 4 cases are constructed considering DG number. One, two, three and four DGs are integrated in Case2, 3, 4, and 5, respectively, to 33bus system. In the following tables, all sizes of DGs type I are in (MW), while size of DGs Type II are in (MVAr).

The obtained results using BSA for all cases of Scenario1 are given in Table 1. The power loss for Case2, 3, 4, and 5, respectively are 211, 103.966, $87.1669,72.7878$ and $67.67 \mathrm{~kW}$. When we compare power loss of all cases, it is concluded that Case 2 is better than Case1, Case 3 is better than Case2, Case 4 is better than Case3, and Case5 is the best for Scenario1.

Power loss reduction (considering Case1) comparison of the proposed algorithm, GA, and other results for all cases of scenario1 are given in Table 2. It is noticed that, the obtained results by the proposed algorithm for all cases are the best among all results.

Table 1. Results by BSA of all cases in Scenario 1 for IEEE 33- bus system

\begin{tabular}{|c|c|c|c|c|c|}
\cline { 2 - 6 } \multicolumn{1}{c|}{} & Case 1 & Case 2 & Case 3 & Case 4 & Case 5 \\
\hline Power loss & 211 & 103.966 & 87.1669 & 72.7878 & 67.76 \\
\hline Placement & & & & $0.8000(13)$ & $0.8400(7)$ \\
and size of & - & $2.5753(6)$ & $0.8516(13)$ & $1.0880(24)$ & $0.6468(14)$ \\
DG Type I & & & $1.1576(30)$ & $1.0523(30)$ & $0.7307(25)$ \\
& & & & & $0.8112(31)$ \\
\hline
\end{tabular}

Table 2. Comparison of power loss reduction (\%) by BSA and others for Scenario 1 of IEEE 33-bus system

\begin{tabular}{|c|c|c|c|c|c|c|c|c|c|}
\hline Case & $\begin{array}{c}\text { Ref. } \\
{[1]}\end{array}$ & $\begin{array}{c}\text { Ref. } \\
{[2]}\end{array}$ & $\begin{array}{c}\text { Ref. } \\
{[5]}\end{array}$ & $\begin{array}{c}\text { Ref. } \\
{[6]}\end{array}$ & $\begin{array}{c}\text { Ref. } \\
{[7]}\end{array}$ & $\begin{array}{c}\text { Ref. } \\
{[11]}\end{array}$ & $\begin{array}{c}\text { Ref. } \\
{[13]}\end{array}$ & GA & BSA \\
\hline 2 & 45.36 & - & - & 39.73 & - & 47.37 & 47.31 & 45.6 & 50.73 \\
\hline 3 & - & - & - & 54.54 & - & 58.68 & 58.64 & 58.65 & 58.69 \\
\hline 4 & - & 27.82 & 61.12 & 56.14 & - & 65.45 & 65.46 & 65.31 & 65.50 \\
\hline 5 & - & - & - & - & 67.68 & - & - & 67.50 & 67.89 \\
\hline
\end{tabular}

Scenario 2: $\quad$ The obtained results using BSA for all cases of Scenario2 are given in Table 3. The power loss for Case 2, 3, 4, and 5, respectively are 211, 67.739, 28.593, 12.2118 and $8.5364 \mathrm{~kW}$. When we compare power loss of all cases, it is concluded that Case 2 is better than Case1, Case 3 is better than Case2, Case 4 is better than Case3, and Case 5 is the best for Scenario2.

Comparison of power loss reduction of BSA and other for all cases of scenario 2 are given in Table 4 . It is noticed that the obtained results by BSA for all cases of scenario 2 are the best among all results.

Table 3. Results by BSA of all cases in Scenario 2 for IEEE 33- bus system

\begin{tabular}{|c|c|c|c|c|c|}
\hline & Case 1 & Case 2 & Case 3 & Case 4 & Case 5 \\
\hline Power loss & 211 & 67.739 & 28.593 & 12.2118 & 8.5364 \\
\hline $\begin{array}{l}\text { Placement } \\
\text { and size of } \\
\text { DG Type I }\end{array}$ & - & $2.5566(6)$ & $\begin{array}{l}0.3964(13) \\
1.0276(30)\end{array}$ & $\begin{array}{l}0.8534(13) \\
0.9229(24) \\
0.3437(30)\end{array}$ & $\begin{array}{c}0.4350(7) \\
0.7180(14) \\
1.0174(24) \\
1.0151(30)\end{array}$ \\
\hline Placement & - & & $0.7537(13)$ & $0.3676(13)$ & $0.5289(7)$ \\
\hline
\end{tabular}




\begin{tabular}{|c|l|l|l|l|l|}
\hline and size of & & $1.7580(6)$ & $0.9009(30)$ & $0.4642(24)$ & $0.247714)$ \\
DG Type II & & & & $0.1949(30)$ & $0.5040(24)$ \\
& & & & & $0.8370(30)$ \\
\hline
\end{tabular}

Table 4. Comparison of power loss reduction (\%) by BSA and others for Scenario 2 of IEEE 33-bus system

\begin{tabular}{|c|c|c|c|}
\hline Case & Ref. [1] & GA & BSA \\
\hline 2 & 67.79 & 67.89 & 67.89 \\
\hline 3 & - & 86.44 & 86.45 \\
\hline 4 & - & 93.00 & 94.21 \\
\hline 5 & - & 95.56 & 95.95 \\
\hline
\end{tabular}

Scenario 3: The obtained results by BSA for all cases of Scenario3 are given in Table 5. The power loss for Case 2, 3, 4, and 5, respectively are 211, 29.8235, $13.8957,8.7463$ and $7.4533 \mathrm{~kW}$. When we compare power loss of all cases, it is concluded that Case 2 is better than Case1, Case 3 is better than Case2, Case 4 is better than Case3, and Case5 is the best among all cases in Scenario3.
In Table 5, all values in bold font indicate that DG pairs (one of type I \& one of type II) are connected in the same bus, while others are connected in different buses. Power loss reduction of BSA and GA results for all cases of scenario 3 are given in Table 6 . It is noticed that the obtained results by the proposed algorithm for all cases are better than GA results.

Table 6. Comparison of power loss reduction (\%) by BSA and others for Scenario 3 of IEEE 33-bus system

\begin{tabular}{|c|c|c|}
\hline Case & GA & BSA \\
\hline 2 & 83.28 & 85.87 \\
\hline 3 & 93.00 & 93.41 \\
\hline 4 & 94.51 & 95.86 \\
\hline 5 & 95.67 & 96.47 \\
\hline
\end{tabular}

Table 5. Results by BSA of all cases in Scenario 3 for IEEE 33-bus system

\begin{tabular}{|c|c|c|c|c|c|}
\hline & Case 1 & Case 2 & Case 3 & Case 4 & Case 5 \\
\hline Power loss & 211 & 29.8235 & 13.8957 & 8.7463 & 7.4533 \\
\hline $\begin{array}{l}\text { Placement } \\
\text { and size of } \\
\text { DG Type I }\end{array}$ & - & $\begin{array}{l}0.6247(29) \\
\mathbf{0 . 6 7 5 5 ( 1 4 )}\end{array}$ & $\begin{array}{l}1.0070(24) \\
0.6972(30) \\
\mathbf{0 . 7 8 3 3}(\mathbf{1 3}) \\
\mathbf{0 . 3 2 9 5}(\mathbf{3 0})\end{array}$ & $\begin{array}{l}0.5724(3) \\
0.4820(12) \\
0.4270(27) \\
\mathbf{0 . 3 7 8 1}(\mathbf{1 3}) \\
\mathbf{0 . 9 0 9 4}(\mathbf{2 4}) \\
\mathbf{0 . 7 6 7 3 ( 3 0 )}\end{array}$ & $\begin{array}{l}0.2647(25) \\
0.3866(26) \\
0.3918(31) \\
\mathbf{0 . 7 9 6 2 ( 1 3 )} \\
\mathbf{0 . 1 0 0 0}(\mathbf{2 1}) \\
\mathbf{0 . 6 2 8 3}(\mathbf{2 4}) \\
\mathbf{0 . 2 0 6 8}(\mathbf{2 8}) \\
\mathbf{0 . 1 7 3 4}(\mathbf{3 1})\end{array}$ \\
\hline $\begin{array}{l}\text { Placement } \\
\text { and size of } \\
\text { DG Type II }\end{array}$ & & $\begin{array}{l}0.1000(30) \\
\mathbf{0 . 3 7 8 1}(\mathbf{1 4})\end{array}$ & $\begin{array}{l}0.2393(8) \\
0.1261(14) \\
\mathbf{0 . 2 0 7 6 ( 1 3 )} \\
\mathbf{0 . 9 6 8 5 ( 3 0 )}\end{array}$ & $\begin{array}{c}0.3194(4) \\
0.1321(10) \\
0.3987(31) \\
\mathbf{0 . 1 0 0 0 ( 1 3 )} \\
\mathbf{0 . 3 8 7 1 ( 2 4 )} \\
\mathbf{0 . 6 5 9 5 ( 3 0 )}\end{array}$ & $\begin{array}{l}0.3439(23) \\
0.4105(27) \\
0.5653(30) \\
\mathbf{0 . 2 7 3 2}(\mathbf{1 3}) \\
\mathbf{0 . 1 3 9 3}(\mathbf{2 1}) \\
\mathbf{0 . 1 0 0 0}(\mathbf{2 4}) \\
\mathbf{0 . 2 0 9 3}(28) \\
\mathbf{0 . 1 0 0 0}(\mathbf{3 1})\end{array}$ \\
\hline
\end{tabular}

\subsection{IEEE 69- bus system}

The IEEE 33-bus system is selected, with system voltage base of $12.66 \mathrm{kV}$ for all cases, and base apparent power of 100 MVA for all cases. The test system has total active and reactive loads of $3.802 \mathrm{MW}$ and 2.694 MVAr, respectively. The data for the line reactance and resistances, and for the loads connected to nodes, are given in [20].

Scenario 1: The obtained results using BSA for all cases of Scenario1 are given in Table 7. The power loss for Case 2, 3, 4, and 5, respectively are 225, 83.0704, 71.567, 69.3767 and $67.84 \mathrm{~kW}$. When we compare power loss of all cases, it is concluded that Case 2 is better than Case1, Case 3 is better than Case2, Case 4 is better than Case3,

and Case5 is the best for Scenario1. Comparison of power loss reduction of BSA and other for all cases of scenario1 are given in Table 8. It is noticed that, the obtained results by BSA for all cases of scenario1 are the best among all results.

Table 7. Results by BSA of all cases in Scenario 1 for IEEE 69-bus system 


\begin{tabular}{|c|c|c|c|c|c|}
\hline & Case 1 & Case 2 & Case 3 & Case 4 & Case 5 \\
\hline $\begin{array}{c}\text { Power } \\
\text { loss }\end{array}$ & 225 & 83.0704 & 71.567 & 69.3767 & 67.84 \\
\hline $\begin{array}{l}\text { Place- } \\
\text { ment and } \\
\text { size of } \\
\text { DG Type } \\
\text { I }\end{array}$ & - & $\begin{array}{c}1.8710 \\
(61)\end{array}$ & $\begin{array}{c}0.5291 \\
(17) \\
1.7820 \\
(61)\end{array}$ & $\begin{array}{c}0.5885 \\
(11) \\
0.3445 \\
(20) \\
1.7338 \\
(61) \\
\end{array}$ & $\begin{array}{l}0.5448(11) \\
0.3572(20) \\
0.7188(50) \\
1.7181(61)\end{array}$ \\
\hline
\end{tabular}

5.7156 and $2.0784 \mathrm{~kW}$. When we compare power loss of all cases, it is found that Case2 is better than Case1, Case 3 is better than Case2, Case4 is better than Case3, and Case 5 is the best for Scenario2.

Power loss reduction comparison of the proposed algorithm, GA, and other results for all cases of the scenario 2 are given in Table 10. It is noticed that, the obtained results by BSA for all cases are the best among all results.

Scenario 2: The obtained results by BSA for all cases of Scenario2 are given in Table 9. The power loss for Case 2, 3, 4, and 5, respectively are 225, 23.133, 7.7836,

Table 8. Comparison of power loss reduction (\%) by BSA and others for Scenario 1 of IEEE 69-bus system

\begin{tabular}{|c|c|c|c|c|c|c|c|}
\hline Case & $\begin{array}{c}\text { Ref. } \\
{[1]}\end{array}$ & $\begin{array}{c}\text { Ref. } \\
{[5]}\end{array}$ & $\begin{array}{c}\text { Ref. } \\
{[11]}\end{array}$ & $\begin{array}{c}\text { Ref. } \\
{[12]}\end{array}$ & $\begin{array}{c}\text { Ref. } \\
{[13]}\end{array}$ & GA & BSA \\
\hline 2 & 62.94 & - & 63.01 & 63.02 & 62.95 & 63.08 & 63.08 \\
\hline 3 & - & - & 68.14 & - & 68.09 & 68.19 & 68.19 \\
\hline 4 & - & 65,68 & 69.14 & - & 69.09 & 69.07 & 69.17 \\
\hline 5 & - & - & - & - & - & 69.80 & 69.85 \\
\hline
\end{tabular}

Table 9. Results by BSA of all cases in Scenario 2 for IEEE 69-bus system

\begin{tabular}{|c|c|c|c|c|c|}
\cline { 2 - 6 } \multicolumn{1}{c|}{} & Case 1 & Case 2 & Case 3 & Case 4 & Case 5 \\
\hline Power loss & 225 & 23.133 & 7.7836 & 5.7156 & 2.0784 \\
\hline Placement & & & & & \\
and size of & - & $2.0275(61)$ & $0.5280(15)$ & $0.3037(19)$ & $0.2774(11)$ \\
DG Type I & & & $1.7266(61)$ & $1.6533(61)$ & $0.2575(18)$ \\
& & & $0.1501(66)$ & $0.5289(49)$ \\
& & & & $1.1995(61)$ \\
\hline Placement & & & $0.4654(15)$ & $0.2203(19)$ & $0.5206(11)$ \\
and size of & - & \multirow{2}{*}{$1.4447(61)$} & $1.2207(61)$ & $1.1344(61)$ & $0.3569(18)$ \\
DG Type II & & & & $0.3391(66)$ & $0.7771(49)$ \\
& & & & & $1.6666(61)$ \\
\hline
\end{tabular}

Table 10. Comparison of power loss reduction (\%) by BSA and others for Scenario 2 of IEEE 69-bus system

\begin{tabular}{|c|c|c|c|}
\hline Case & Ref. [1] & GA & BSA \\
\hline 2 & 89.01 & 89.72 & 89.72 \\
\hline 3 & - & 96.23 & 96.54 \\
\hline 4 & - & 96.48 & 97.46 \\
\hline 5 & - & 97.37 & 99.08 \\
\hline
\end{tabular}

Scenario 3: The obtained results by proposed algorithm for all cases of Scenario3 are given in Table 11. The power loss for Case2, 3, 4, and 5, respectively are 225, $7.3167,4.1776,3.6989$ and $1.8875 \mathrm{~kW}$. When we compare power loss of all cases, it is noticed that Case2 is better than Case1, Case 3 is better than Case2, Case4 is better than Case3, and Case5 is the best for Scenario3. In Table 11, all values in bold font indicate that DG pairs (one of type I \& one of type II) are connected in the same bus, while others are connected in different buses.

In Table 12, comparison of power loss reduction of the proposed algorithm and GA for cases of scenario 3 is given. It is noticed that the obtained results by BSA for all cases of scenario 3 are better than GA results.

Table 12. Comparison of power loss reduction (\%) by BSA and others for Scenario 3 of IEEE 69-bus system

\begin{tabular}{|c|c|c|}
\hline Case & GA & BSA \\
\hline 2 & 96.64 & 96.75 \\
\hline 3 & 97.63 & 98.14 \\
\hline 4 & 97.94 & 98.36 \\
\hline 5 & 99.01 & 99.16 \\
\hline
\end{tabular}


Table 11. Results by BSA of all cases in Scenario 3 for IEEE 69-bus system

\begin{tabular}{|c|c|c|c|c|c|}
\hline & Case 1 & Case 2 & Case 3 & Case 4 & Case 5 \\
\hline Power loss & 225 & 7.3167 & 4.1776 & 3.6989 & 1.8875 \\
\hline $\begin{array}{l}\text { Placement } \\
\text { and size of } \\
\text { DG Type I }\end{array}$ & & $\begin{array}{l}0.5126(17) \\
\mathbf{1 . 7 8 0 5 ( 6 1 )}\end{array}$ & $\begin{array}{l}0.4080(17) \\
0.3148(50) \\
\mathbf{1 . 8 0 0 0 ( 6 1 )} \\
\mathbf{0 . 3 3 8 7 ( 6 6 )}\end{array}$ & $\begin{array}{c}0.6224(8) \\
0.1440(17) \\
0.6551(50) \\
\mathbf{0 . 2 6 3 0}(\mathbf{2 1}) \\
\mathbf{0 . 7 8 4 8 ( 6 1 )} \\
\mathbf{0 . 8 7 5 9 ( 6 2 )}\end{array}$ & $\begin{array}{c}0.2696(4) \\
0.3414(19) \\
0.2383(53) \\
0.3477(12) \\
\mathbf{0 . 5 3 5 9}(\mathbf{5 0}) \\
\mathbf{0 . 1 0 0 0}(\mathbf{6 1}) \\
\mathbf{1 . 2 0 0 0}(\mathbf{6 2}) \\
\mathbf{0 . 3 6 7 4 ( 6 4 )}\end{array}$ \\
\hline $\begin{array}{l}\text { Placement } \\
\text { and size of } \\
\text { DG Type II }\end{array}$ & - & $\begin{array}{l}0.3400(16) \\
\mathbf{1 . 2 4 8 3 ( 6 1 )}\end{array}$ & $\begin{array}{l}0.1000(15) \\
0.608449) \\
\mathbf{1 . 1 7 9 2 ( 6 1 )} \\
\mathbf{0 . 4 6 4 5 ( 6 6 )}\end{array}$ & $\begin{array}{l}0.3180(12) \\
0.2186(40) \\
0.3273(53) \\
\mathbf{0 . 1 0 0 0}(\mathbf{2 1}) \\
\mathbf{0 . 2 4 0 0 ( 6 1 )} \\
\mathbf{0 . 8 7 4 5 ( 6 2 )}\end{array}$ & $\begin{array}{c}0.2734(2) \\
0.1314(15) \\
0.1757(49) \\
0.3036(12) \\
\mathbf{0 . 3 6 5 4 ( 5 0 )} \\
\mathbf{0 . 3 0 9 4}(61) \\
\mathbf{0 . 5 4 6 4 ( 6 2 )} \\
\mathbf{0 . 3 5 3 2}(64)\end{array}$ \\
\hline
\end{tabular}

Variation of fitness function versus iteration number of IEEE 33- and 69-bus system for Scenario-3 are shown in Fig. 1 and 2, respectively. In Fig.1, the value of fitness nearly at $62^{\text {nd }}, 50^{\text {th }}, 45^{\text {th }}$ and $52^{\text {nd }}$ iteration for Case 2, 3, 4 , and 5, respectively; in Fig.2, the value of fitness nearly at $74^{\text {nd }}, 46^{\text {th }}, 52^{\text {th }}$ and $53^{\text {th }}$ iteration for Case 2,3 ,

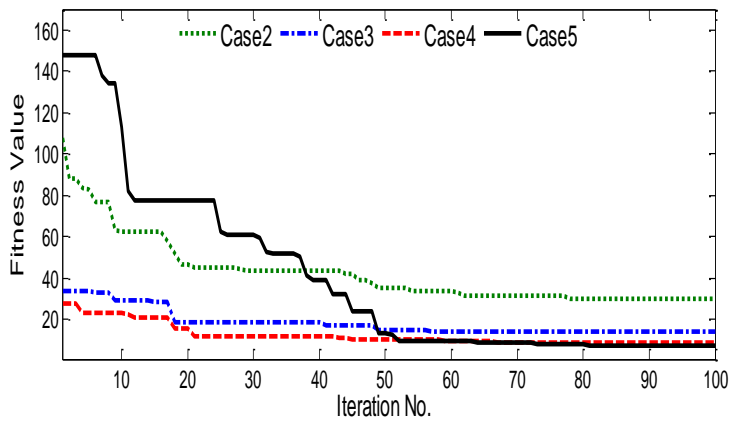

Figure 1. Fitness variation with iteration number for 33 bus system with scenario3

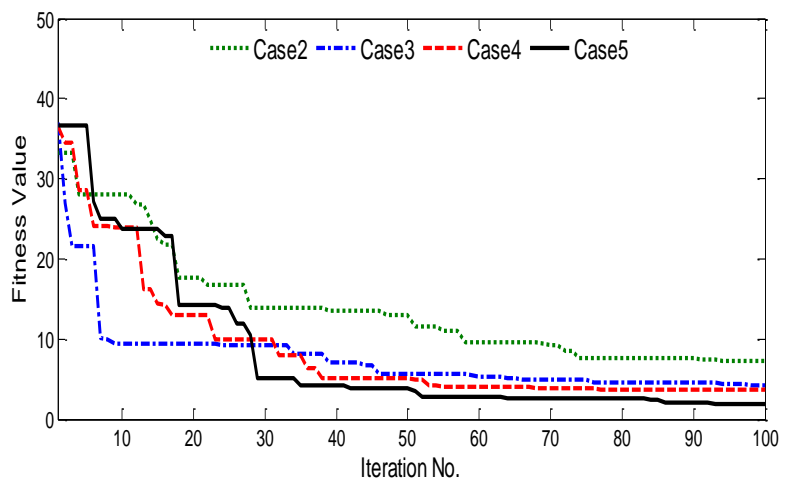

Figure 2. Fitness variation with iteration number for 69 bus system with scenario 3
4 , and 5, respectively are approached to the optimal solution.

It can be seen from the figures that all fitness values are reached the optimal solution before $75^{\text {th }}$ iteration and there is no change after that.

Summary: According to the obtained results by BSA for all scenarios and cases of both test systems, it is noted that power loss reduction gradually increases as the number of DGs is increased, as well as by changing the DG type, as shown in Fig. 3 and 4. It is clearly observed that the results of Case 5 of each scenarios offer the greatest power loss reduction for both the IEEE 33- and 69-bus system. The noticeable increase in power loss reduction under Scenario-3 is better than those in other scenarios. So, it is better to integrate some DGs, as in Scenario-3, in order to increase the power loss reduction. The location, size, type, and the number of DGs are the basic steps for planning improvements in system performance, especially the system power loss.

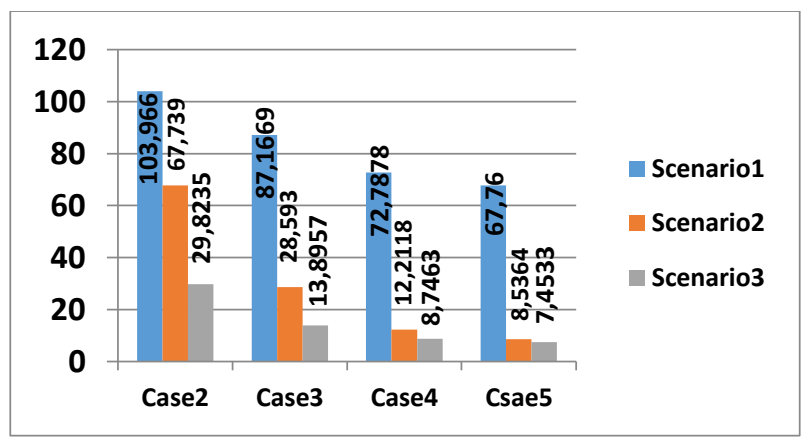

Figure 3. Demonstrate power loss $(\mathrm{kW})$ in each scenario with their different cases for 33 bus system 


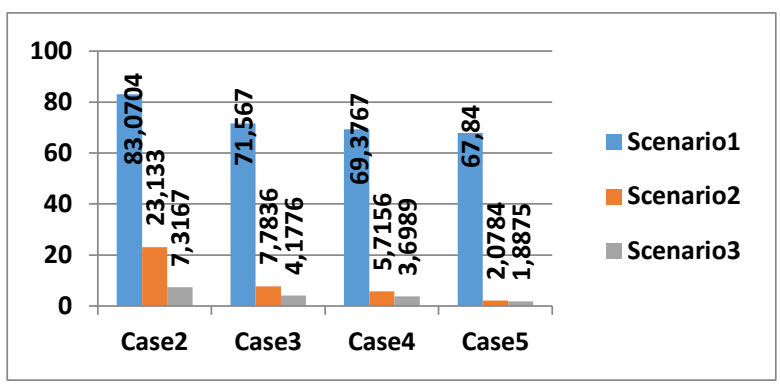

Figure 4. Demonstrate power loss $(\mathrm{kW})$ in each scenario with their different cases for 69 bus system

\section{Conclusion}

In this work, the BSA is successfully applied in RDS to find optimal size, number, type, and location of DGs. These DGs are connected to the test systems and minimized their power loss. The DGs are integrated under 3 scenarios and 5 cases in each scenario. Under Scenario-3 (Case5), power loss is reduced by $99.16 \%$, $96.47 \%$, respectively for 33 and 69 bus systems. It's noticed that it is better to select suitable DG type to minimize power loss to a considerable amount. But the best way is to put DG type, and number in consideration.

It is concluded that an optimal size, type, number of DG with suitable location can reduce the power losses by considerable amounts.

In future work, Type III: Generating active and absorbing reactive power (wind power) and Type IV: Generating active and reactive power (synchronous generator) will considered by using the BSA.

\section{Nomenclature}

$\begin{array}{ll}\text { DG } & \text { Distributed generation } \\ f & \text { Fitness function } \\ g & \text { Equality constraint } \\ h & \text { Inequality constraint } \\ x & \text { Control variables } \\ u & \text { State variables } \\ P_{\text {loss }} & \text { Total power loss } \\ P_{\text {feeder }} & \text { Feeder active power } \\ Q_{\text {feeder }} & \text { Feeder reactive power } \\ P_{D G, i} & \text { DG active power output at } i^{\text {th }} \\ P_{L o a d, i} & \text { bus } \\ Q_{\text {Load }, i} & \text { Active load at } i^{\text {th }} \text { bus } \\ N & \text { Reactive load at } i^{t h} \text { bus } \\ N_{D G} & \text { Total bus number } \\ N_{S C} & \text { Total number of DG }\end{array}$

\begin{tabular}{|c|c|}
\hline$C F_{i}$ & Status (on/off) of the feeder \\
\hline$C D G_{i}$ & $\begin{array}{l}\text { Status (on/off) of the distributed } \\
\text { generation at } i^{t h} \text { bus }\end{array}$ \\
\hline$C S C_{i}$ & $\begin{array}{l}\text { Status (on/off) of the } \\
\text { synchronous compensator at } i^{t h} \\
\text { bus }\end{array}$ \\
\hline$V_{i}$ & Voltage magnitude at $i^{\text {th }}$ bus \\
\hline$\delta_{i j}$ & $\begin{array}{l}\text { The voltage angle difference } \\
\text { between buses } i \text { and } j\end{array}$ \\
\hline$Q_{s c, i}$ & $\begin{array}{l}\text { SC reactive power output at } i^{t h} \\
\text { bus }\end{array}$ \\
\hline$G_{i j}$ & $\begin{array}{l}\text { Transfer conductance between } \\
\text { buses } i \text { and } j\end{array}$ \\
\hline $\begin{array}{l}\mathrm{SC} \\
S N\end{array}$ & $\begin{array}{l}\text { Synchronous compensator } \\
\text { Number of population size }\end{array}$ \\
\hline D & $\begin{array}{l}\text { the number of optimization } \\
\text { parameters }\end{array}$ \\
\hline Randshuff & random mixing function \\
\hline Rand (low, up $)$ & $\begin{array}{l}\text { produce a random number } \\
\text { between low and up }\end{array}$ \\
\hline Pop & Population \\
\hline oldPop & Old population \\
\hline$\sim$ & Produce \\
\hline Tрор & Trial population \\
\hline$P_{D G, i}^{\min }$ & $\begin{array}{l}\text { Minimum DG active power } \\
\text { output at } i^{\text {th }} \text { bus }\end{array}$ \\
\hline$P_{D G, i}^{\max }$ & $\begin{array}{l}\text { Maximum DG active power } \\
\text { output at } i^{\text {th }} \text { bus }\end{array}$ \\
\hline$I_{i j}$ & Current magnitude at branch $i j$ \\
\hline$I_{i j}^{\max }$ & $\begin{array}{l}\text { Allowable maximum current } \\
\text { magnitude at branch } \ddot{i j}\end{array}$ \\
\hline$a, b$ & $\operatorname{Rand}(0,1)$ \\
\hline$:=$ & Update operator \\
\hline mutantPop & Population of mutation \\
\hline$W$ & Value \\
\hline randn & $\begin{array}{l}\text { Generates numbers between } 0 \text {, } \\
1\end{array}$ \\
\hline map & Matrix $(S N * D)$ \\
\hline$Q_{s c, i}^{\min }$ & $\begin{array}{l}\text { Minimum SC reactive power } \\
\text { output at } i^{t h} \text { bus }\end{array}$ \\
\hline$Q_{s c, i}^{\max }$ & $\begin{array}{l}\text { Maximum SC reactive power } \\
\text { output at } i^{\text {th }} \text { bus }\end{array}$ \\
\hline$B_{i j}$ & $\begin{array}{l}\text { Transfer susceptance between } \\
\text { buses } i \text { and } j\end{array}$ \\
\hline
\end{tabular}




\section{Author's Contributions}

Waleed Fadel: Methodology, Software.

Ulas Kilic: Visualization, Investigation, Supervision.

Sezai Taskin: Investigation, Supervision, Writing.

\section{Ethics}

There are no ethical issues after the publication of this manuscript.

\section{References}

1. Kansal, S., Kumar, V. and Tyagi, B., 2013. Optimal placement of different type of DG sources in distribution networks. International Journal of Electrical Power \& Energy Systems, 53, pp.752-760.

2. Kayal, P. and Chanda, C.K., 2013. Placement of wind and sola based DGs in distribution system for power loss minimization and voltage stability improvement. International Journal of Electrical Power \& Energy Systems, 53, pp.795-809.

3. Kollu, R., Rayapudi, S.R. and Sadhu, V.L.N., 2014. A novel method for optimal placement of distributed generation in distribution systems using HSDO. International Transactions on Electrical Energy Systems, 24(4), pp.547-561.

4. García, J.A.M. and Mena, A.J.G., 2013. Optimal distributed generation location and size using a modified teaching-learning based optimization algorithm. International journal of electrical power \& energy systems, 50, pp.65-75.

5. Injeti, S.K. and Kumar, N.P., 2013. A novel approach to identify optimal access point and capacity of multiple DGs in a small, medium and large scale radial distribution systems. International Journal of Electrical Power \& Energy Systems, 45(1), pp.142-151.

6. Manafi, H., Ghadimi, N., Ojaroudi, M. and Farhadi, P., 2013 Optimal placement of distributed generations in radial distribution systems using various PSO and DE algorithms. Elektronika ir Elektrotechnika, 19(10), pp.53-57.

7. Moradi, M.H. and Abedini, M., 2012. A combination of genetic algorithm and particle swarm optimization for optimal DG location and sizing in distribution systems. International Journal of Electrical Power \& Energy Systems, 34(1), pp.66-74.

8. Aman, M.M., Jasmon, G.B., Bakar, A.H.A. and Mokhlis, H., 2013. A new approach for optimum DG placement and sizing based on voltage stability maximization and minimization of power losses. Energy Conversion and Management, 70, pp.202-210.

9. Ates, Y., Gokcek, T. and Arabul A. Y., 2020, Impact of hybrid power generation on voltage, losses, and electricity cost in distribution networks. Turkish Journal of Electrical Engineering \& Computer Sciences, 1-16.

10. Turan, M.T., Ates, Y., Erdinc, O., Gokalp, E. and Catalão, J.P., 2019. Effect of electric vehicle parking lots equipped with roof mounted photovoltaic panels on the distribution network. International Journal of Electrical Power \& Energy Systems, 109, pp.283-289.

11. Hemeida, M.G., Ibrahim, A.A., Mohamed, A.A.A., Alkhalaf, S and El-Dine, A.M.B., 2020. Optimal allocation of distributed generators DG based Manta Ray Foraging Optimization algorithm (MRFO). Ain Shams Engineering Journal.

12. Memarzadeh, G. and Keynia, F., 2020. A new index-based method for optimal DG placement in distribution networks. Engineering Reports, 2(10), p.e12243.Kayal, P. and Chanda, C.K., 2013. Placement of wind and solar based DGs in distribution system for power loss minimization and voltage stability improvement. International Journal of Electrical Power \& Energy Systems, 53, pp.795-809.

13. Kansal, S., Kumar, V. and Tyagi, B., 2016. Hybrid approach for optimal placement of multiple DGs of multiple types in distribution networks. International Journal of Electrical Power \& Energy Systems, 75, pp.226-235.

14. Fadel, W., Kilic, U. and Taskin, S., 2017. Placement of Dg, Cb and Tcsc in radial distribution system for power loss minimization using back-tracking search algorithm. Electrical Engineering, 99(3), pp.791-802

15. Aman, M.M., Jasmon, G.B., Bakar, A.H.A. and Mokhlis, H., 2014. A new approach for optimum simultaneous multi-DG distributed generation Units placement and sizing based on maximization of system loadability using HPSO (hybrid particle swarm optimization) algorithm. Energy, 66, pp.202-215.

16. Civicioglu, P., 2013. Backtracking search optimization algorithm for numerical optimization problems. Applied Mathematics and Computation, 219(15), pp.8121-8144.

17. Kilıç, U., 2015. Backtracking search algorithm-based optimal power flow with valve point effect and prohibited zones. Electrical Engineering, 97(2), pp.101-110.

18. Song, X., Zhang, X., Zhao, S. and Li, L., 2015. Backtracking search algorithm for effective and efficient surface wave analysis. Journal of Applied Geophysics, 114, pp.19-31.

19. Duan, H. and Luo, Q., 2014. Adaptive backtracking search algorithm for induction magnetometer optimization. IEEE Transactions on Magnetics, 50(12), pp.1-6.

20. Moradi, M.H., Zeinalzadeh, A., Mohammadi, Y. and Abedini, M., 2014. An efficient hybrid method for solving the optimal sitting and sizing problem of DG and shunt capacitor banks simultaneously based on imperialist competitive algorithm and genetic algorithm. International Journal of Electrical Power \& Energy Systems, 54, pp.101-111. 